\title{
MEDIATING EFFECT OF EMOTIONAL INTELLIGENCE ON TRANSFORMATIONAL LEADERSHIP AND EMPLOYEE PERFORMANCE: CENTRIC TO SELECT PUBLIC SECTOR HOSPITALS IN COASTAL ANDHRA PRADESH, INDIA
}

\begin{tabular}{|c|c|}
\hline Mrs.D.S.V. Krishna Kumari ${ }^{1}$ & $\begin{array}{l}{ }^{1} \text { Research Scholar, Dept. of HRM, Acharya } \\
\text { Nagarjuna University, Guntur- 522 510, A.P. }\end{array}$ \\
\hline Dr. B. Sreedhar Reddy ${ }^{2}$ & $\begin{array}{l}{ }^{2} \text { Guest Faculty, Dept. of MBA }(H \text { A) Acharya } \\
\text { Nagarjuna University, Guntur-522 510, A.P. }\end{array}$ \\
\hline Dr. V. Tulasi Das ${ }^{3}$ & $\begin{array}{c}{ }^{3} \text { Assoc. Professor, Chairman BoS, Dept. of HRM, } \\
\text { Acharya Nagarjuna University, Guntur-522 510, } \\
\text { A.P. }\end{array}$ \\
\hline
\end{tabular}
ABSTRACT
DOI No: 10.36713/epra6525
Article DOI URL: https://doi.org/10.36713/epra6525

Employee performance assessment is one of the most important functions of human resources management. It starts immediately after the employees get hired and goes further throughout the employment process. Emotional intelligence is considered to have a greater impact on the performance of nurses and groups as measured against traditional intelligence. Emotionally intelligent nurses in the organization result in better overall organisational performance. But emotional intelligence alone not able to define the changes in employee performance and from the literature it is found that leadership has indirect effect on employee performance but majority of the researchers are not considering leadership indirect affect while preparing employee performance model. In this context present research validates the mediating effect of emotional intelligence on transformational leadership and employee performance.

KEY WORDS: Employee Performance, Emotional Intelligence, Transformational Leadership, Achievement, Mediating Effect.

\section{INTRODUCTION}

Human resources as one of the resources in the organization play an important role in the successful achievement of organizational goals. In the development of human resources, the performance of an employee in a company is needed to achieve employee performance itself and also for the success of the company. Improving the performance of these employees is not only beneficial for the company, but also for the employees themselves. Because with good performance theoretically can achieve a better level of employee career development (Siahaan et al., 2016). Leadership style is one of the important factors that can affect the performance of employees in a company. Emotional intelligence is considered to have a greater impact on the performance of nurses and groups as measured against 
traditional intelligence. Emotional Intelligence becomes a more important factor and ability needed by nurses to confront with the hospital environment. As nurses are well known to the patient's strengths and weaknesses thoroughly, they can be good guides and counsellors for the patients in hospitals. Such nurses can visualize the pros and cons of any situation and are able to initiate change with courage and confidence. Nurses with high self-awareness are fully aware of their feelings, emotions, when they interact with the patients to assess their problems exactly. Leadership style is the ability of a leader in directing, influencing, encouraging and controlling subordinates to be able to do work on their awareness and volunteering in achieving a certain goal. The success and failure of a company or organization is determined by leadership, an effective form of leadership will have an impact on the progress of the company or organization in facing the challenges and changes that occur. The nature of a leader is very influential in the style of leadership to determine the success of being a successful leader, and is determined by the personal abilities of the leader. Personal ability in question is the quality of a person with various traits, temperaments or characteristics inside. From the literature it is found that leadership has indirect effect on employee performance but majority of the researchers are not considering leadership indirect affect while preparing employee performance model. In this context present research validates the mediating effect of emotional intelligence on transformational leadership and employee performance.

\section{Emotional Intelligence and Job Performance}

Sakshi Singh et al. (2019) concluded that there was a positive significant relationship between the emotional intelligence and job performance satisfaction of the nursing personnel. The majority of the nurses in the study have proficient level of emotional intelligence and job performance satisfaction and nurses' scores on emotional intelligence tend to be positively correlated with their scores on job satisfaction. Ranjbar Ezzatabadi $M$ et al. (2012) suggested that emotional intelligence competency should be overseen through a specific relevant, hierarchical or administrative circumstance. The emotionally astute nursing staffs are bound to convey excellent administrations that pointed in numerous administrative activities in the wellbeing area as of late.

\section{Transformational Leadership and Job Performance}

Vishnu Renjith, Renu G, Anice George (2014) said that Transformational leadership has got wide implications in nursing leadership and is a powerful management strategy for nurse leaders. It empowers nurse leaders to execute change viably and is a basic medium to build up a viable nursing labor force. Owen Doody and Catriona M Doody (2012) observed that Transformational leadership recognises the importance of rewards, but goes further to satisfy the emotional and intellectual needs of staff. Transformational leaders establish strong conditions where duty is shared and staffs have a sense of security to face challenges to get imaginative and advance. Krepia V et al. (2018) said that positive impact that transformational leaders have on the working performance of representatives is obvious. In any case, the specific mental instruments that could clarify the relationships between transformational leaders and the work performance of staff are not yet known. These instruments incorporate additionally, practices that are not formal employment prerequisites, but rather they encourage the smooth working of the organization as a social framework.

\section{Emotional Intelligence and Transformational Leadership}

Ali Akbar Behbahani (2011) observed that emotional intelligence as Goleman (1998) said is one of the main elements for singular transformation, accomplishment seeing someone, and employment execution. Emotional intelligence assumes a significant function in helping managers and employers at DPESI to get feelings and sentiments of oneself as well as other people and how to respond fittingly to these feelings. Rukmathan R and V. Kavitha (2019) said that Nurses with high mindfulness are completely mindful of their sentiments, feelings, when they communicate with the patients to survey their issues precisely. They take endeavours to learn new zones and show revenue to refresh them. Presently Emotional intelligence is considered to greatly affect the presentation of nurses and gatherings as estimated against conventional intelligence. Emotional intelligence may assist the nurses with coming over the negative circumstance and they likewise recognize their own feelings.

\section{LITERATURE REVIEW}

Suhaila Haron et.al, (2019), article entitled "Validating the Development of Instrument for Measuring Nurses' Performance Scale" published in Journal of Management Info, article demonstrates quantitative indices being used for content validity and reliability of nurse performance questionnaire during design and development stage of the scale. These indices have evidently provided systematic criteria for items' reduction processes comprises two-step judgement process. Some limitations of content validity studies should be noted. First, experts' feedback is subjective; thus, the study is subject to bias that may exist among the experts. Secondly, quantification of content validity alone may results in collapse response category during computation of the index (Beckstead, 2009).

Ranjbar Ezzatabadi M et al., (2012), article entitled "Nurses' Emotional Intelligence Impact on the Quality of Hospital Services" published in Iran Red Cres Med J. suggested that emotional intelligence competency should be overseen through a specific relevant, hierarchical or administrative circumstance. To recommend a few ramifications for human resource management, we may infer that emotionally astute nursing staffs are bound to convey excellent administrations that pointed in 
numerous administrative activities in the wellbeing area as of late.

Jie-Hui Xu (2017), article entitled "Leadership theory in clinical practice" published in Chinese Nursing Research said that Transactional leadership depends on unforeseen rewards and can positively affect supporters' fulfilment and execution. Two other leadership styles regularly utilized in nursing practice are situational leadership and autocratic leadership. Diverse leadership speculations ought to be joined in clinical application in current complex associations. Consequently, the mix of set up leadership styles is strongly suggested for nurse pioneers in clinical settings since different leadership styles and hypotheses are applicable to nursing practice. Nurse supervisors and clinical pioneers ought to recognize the points of interest and burdens of every hypothesis. In any case, the improvement of leadership aptitudes is a progressing venture that starts with knowing and getting oneself.

Efstathios Bakertzis, Barbara Myloni (2019), article entitled "What Is the Mediating Role of Job Burnout in the Relationship between Emotional Intelligence and Job Performance in the Healthcare Sector?" published in The International Journal of Business \& Management suggested that healthcare employees have high emotional abilities and skills, which contributes to the adoption of emotional intelligent behaviours in their workplace, higher communication and creativity and efficient handling with Job Stress and Burnout Syndrome. Emotional intelligence is positively related to Job Performance and negatively related to Job Burnout. We support prior studies that Emotional Intelligence is responsible for the development of positive work behaviours and the provision of quality healthcare service. Emotional intelligent employees are characterized by optimism, efficient emotional management and effective social skills, which allow them to develop positive and efficient relationships with their colleagues and their patients.

Sunardi Idi, Nur Hidayah (2020), article entitled "The Influence of Leadership on Work Motivation and Its Effect on Nurses' Performance in Ward Unit of Morotai Island District Hospital" published in $R A$ Journal of Applied Research observed that that the leadership of the head nurse had a positive effect on work motivation. Leadership is an interpersonal process where a person is able to influence the activities of individuals or groups to achieve the goals set through communication. With leadership someone can provide motivation to workers, become a bull for workers, maintain integrity, act as an intermediary and parental approach. Based on these descriptions, leadership can increase the motivation of subordinates. The results of this study are in accordance with the research of Muhammad et al, which shows that there is a relationship between the leadership of the head of the room on the motivation of the nurses.
LjerkaHajncl, Dario Vučenović (2020), article entitled "Effects of Measures of Emotional Intelligence on the Relationship between Emotional Intelligence and Transformational Leadership" published in Psychological Topics confirmed that leaders in organizational settings consider those who are good in understanding emotions - both others' and their own will practice more transformational behaviour than others who do not have the same level of emotional competence. To establish an accurate picture of the nature of these relationships, further research needs to focus more on using multiple ratings sources for leadership behaviour and on new ways of assessing the validity of EI measures in terms of underlying mental processes that would allow systematic and accurate determination of predictive validity EI in explaining the origin of TL style.

\section{RESEARCH GAP}

Very less literature is available on transformational leadership impact on employee performance and in the hospital sector the literature available is very nominal. In this context this article focuses on transformational leadership impact on employee performance among employees of select public sector hospitals. From the literature it is found that there is extensive research evidences to establish relationship between emotional intelligence and employee performance, but from literature review it is felt that there is a need for a model which can explain the relationship between emotional intelligence and employee performance.

\section{Objectives}

- To examine the level of employee performance among employees of select public sector hospitals in coastal Andhra Pradesh.

- To analyse the emotional intelligence impact on employee performance among employees of select public sector hospitals in coastal Andhra Pradesh.

- To study the transformational leadership impact on employee performance among employees of select public sector hospitals in coastal Andhra Pradesh.

- To examine mediating effect of emotional intelligence on transformational leadership and employee performance among employees of select public sector hospitals in coastal Andhra Pradesh.

\section{HYPOTHESIS}

\section{Hypothesis - 1}

$\mathbf{H}_{\mathbf{0}}$ : The employee does not perceive all the dimensions of employee performance as overall employee performance among employees of select public sector hospitals in coastal Andhra Pradesh.

Hypothesis - 2 
$\mathbf{H}_{0}$ : There is no impact of emotional intelligence on employee performance among employees of select public sector hospitals in coastal Andhra Pradesh.

Hypothesis - 3

$\mathbf{H}_{\mathbf{0}}$ : There is no impact of transformational leadership on employee performance among employees of select public sector hospitals in coastal Andhra Pradesh.

Hypothesis - 4

$\mathbf{H}_{\mathbf{0}}$ : There is no mediating effect of emotional intelligence on transformational leadership and employee performance among employees of select public sector hospitals in coastal Andhra Pradesh.

\section{RESEARCH METHODOLOGY Sources of Data}

To fulfil afore said objectives, the data were collected through both primary and secondary sources. The primary data were collected through survey method by using the standard scales for measurement of Employee Performance (EP), Emotional Intelligence (EI) and Transformational Leadership (TL), The secondary data were collected by using international and national data sources like local library, EBSCO: Master File premier, Business Source premier, Academic Source premier, Google Scholar Search; SAGE journals, HBR Research; JGATEPlus, HBR Podcast; Dialog. Furthermore, sources such as textbooks, Internet, magazines and newspapers were used to complete the literature section of this article.

The participants selected for this study consisted of employees of select public hospitals. Purposive sampling technique was deployed in sample selection. 450 questionnaires are distributed among select public sector hospital employees.

\section{Variables of the study}

For the measurement of the variables standard scales are adopted from literature. Employee Performance is assessed with Rahati Meghdad et.al, (2020) scale with 21 items, Emotional Intelligence is measured with Jessica Tighe (2015) scale with 29 items, Transformational Leadership is measured with Despina Sapountzi-Krepia et.. al, (2019) scale with 39 items and all the scales are coded with Likert scale.

\section{DATA ANALYSIS}

Employee Performance

Values of different fit indices; GFI, IFI, CFI, NFI greater than 0.9 considered as good fit and RMSEA values .05 or less indicates close fit, between 0.05 to 0.08 indicates reasonable fit and values between 0.08 to 0.10 show marginal fir (Kline, 2001). Structural Equation Model (SEM) is conducted with all five variables and data shows that in public sector hospitals $\mathrm{df}=3.809$; $\mathrm{GFI}=.917$; $\mathrm{NFI}=.922 ; \mathrm{IFI}=.933 ; \mathrm{TLI}=.916 ; \mathrm{CFI}=.933$; RMSEA $=.044$. The model is improvised after allowing modification indices.

\section{Emotional Intelligence}

Structural Equation Model (SEM) is conducted with all five variables and data shows that in public sector hospitals $\mathrm{df}=3.615$; $\mathrm{GFI}=.907$; $\mathrm{NFI}=.918$; IFI= $.933 ; \mathrm{TLI}=.923 ; \mathrm{CFI}=.912 ; \mathrm{RMSEA}=.066$. the model is improvised after allowing modification indices.

\section{Transformational Leadership}

Structural Equation Model (SEM) is conducted with all five variables and data shows that in public sector hospital $\mathrm{df}=3.451$; $\mathrm{GFI}=.925$; $\mathrm{NFI}=.949$; $\mathrm{IFI}=$ $.970 ; \mathrm{TLI}=.951 ; \mathrm{CFI}=.969 ; \mathrm{RMSEA}=.052$. The model is improvised after allowing modification indices.

\section{Divergent Validity\& Convergent Validity}

Table - 1: Divergent Validity \& Convergent Validity of Employee Performance among Employees of Select Public Sector Hospitals

\begin{tabular}{|l|c|c|c|c|c|c|c|c|}
\hline & CR & AVE & & EP1 & EP2 & EP3 & EP4 & EP5 \\
\hline EP1 & 0.939049 & 0.755374 & EP1 & 0.869122 & & & & \\
\hline EP2 & 0.981643 & 0.914509 & EP2 & 0.836 & 0.95629943 & & & \\
\hline EP3 & 0.895151 & 0.851285 & EP3 & 0.858 & 0.954 & 0.92265107 & & \\
\hline EP4 & 0.973666 & 0.924963 & EP4 & 0.801 & 0.972 & 0.916 & 0.96175 & \\
\hline EP5 & 0.89438 & 0.849534 & EP5 & 0.716 & 0.866 & 0.87 & 0.846 & \\
\hline
\end{tabular}

Table - 2: Divergent Validity \& Convergent Validity of Emotional Intelligence among Employees of Select Public Sector Hospitals

\begin{tabular}{|l|c|c|c|c|c|c|c|c|}
\hline & CR & AVE & & EP1 & EP2 & EP3 & EP4 & EP5 \\
\hline EP1 & 0.527056 & 0.712849 & EP1 & 0.8443 & & & & \\
\hline EP2 & 0.548279 & 0.758462 & EP2 & 0.835 & 0.87089695 & & & \\
\hline EP3 & 0.525042 & 0.704424 & EP3 & 0.736 & 0.746 & 0.83929956 & & \\
\hline EP4 & 0.53392 & 0.7272 & EP4 & 0.716 & 0.7 & 0.823 & 0.85276 & \\
\hline EP5 & 0.965345 & 0.684785 & EP5 & 0.73 & 0.72 & 0.712 & 0.738 & \\
(Source: Primary data)
\end{tabular}


Table - 3: Divergent Validity \& Convergent Validity of Transformational Leadership among Employees of Select Public Sector Hospitals

\begin{tabular}{|l|c|c|c|c|c|c|c|c|c|}
\hline & CR & AVE & & TL1 & TL2 & TL3 & TL4 & TL5 & TL6 \\
\hline TL1 & 0.995905 & 0.949391 & TL1 & 0.97437 & & & & & \\
\hline TL2 & 0.989223 & 0.87745 & TL2 & 0.953 & 0.93672289 & & & & \\
\hline TL3 & 0.983419 & 0.821306 & TL3 & 0.583 & 0.781 & 0.90625909 & & & \\
\hline TL4 & 0.991776 & 0.903737 & TL4 & 0.478 & 0.67 & 0.905 & 0.95065 & & \\
\hline TL5 & 0.963928 & 0.676314 & TL5 & 0.38 & 0.52 & 0.539 & 0.518 & 0.82238 & \\
\hline TL6 & 0.997722 & 0.971191 & TL6 & 0.377 & 0.519 & 0.519 & 0.501 & 0.788 & \\
\hline
\end{tabular}

(Source: Primary data)

Convergent validity was assessed through $\mathrm{CR}$ and AVE. The required levels of CR and AVE should be equal or more than 0.6 and 0.5 respectively (Hair et. al., 2010). CR and AVE were also used to establish the reliability of the measurement model. $\mathrm{CR}$ is an alternative measure to Cronbach's Alpha; it is recommended by Chin (1998) as an ideal measure to overcome some deficiencies in Cronbach's alpha. The CR should be 0.60 or higher, while the minimum threshold for an AVE should be 0.5 or higher to indicate adequate reliability (Awang, 2015). The composite reliability (CR) and average variance explained (AVE) values for the final measurement model of Transformational Leadership are presented in above table. From the above table it is observed that all CR values are more than 0.7 and AVE values are more than 0.5 , hence supporting their convergent validity (Hair et al., 2010).

The recommended approach for establishing divergent validity is to compare the squared correlation between two constructs with either of their individual AVE estimates (Hair et. al., 1998). The AVE estimates should be greater than the squared correlation estimate. In addition to distinctiveness of constructs, divergent Validity also means that individual measured items should represent only one latent construct. Form the above table it is observed that the AVE estimates are greater than the squared correlation estimates, hence supporting divergent validity (Hair et al., 1998).

\section{Mediating Effect}

Table - 4: Mediating Effect of Emotional Intelligence on Transformational Leadership and Employee Performance in Public Sector Hospitals

\begin{tabular}{|l|c|c|c|c|l|}
\hline & Beta & SE & LLCI & ULCI & Mediation \\
\hline Direct & .1462 & .0513 & .0455 & .2470 & Partial \\
\hline Indirect & .5890 & .0537 & .4836 & .6936 & Mediation \\
\hline
\end{tabular}

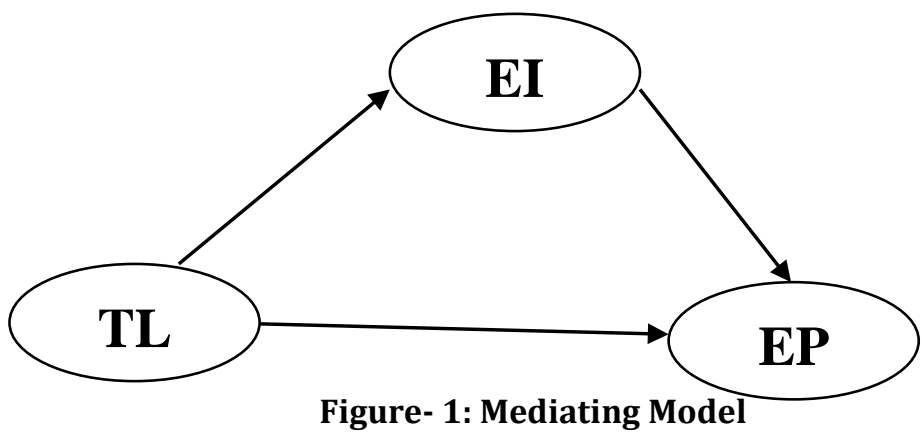

From the analysis it is observed that in the study area Emotional Intelligence has partial mediation effect on Transformational Leadership and Employee Performance.

\section{FINDINGS BASED ON THE STUDY}

$>$ In public sector hospitals employee's awareness of emotion factors are explaining 59.6\% deviation in employee performance. From the ANOVA table it is observed that awareness of emotions factors of emotional intelligence are significantly impacting employee performance. Employee performance can be explained by constant value 1.133 and I can clarify the emotions I feel to colleague's beta value .194, I can talk about the emotions I feel to other colleague's beta value .258 , I can converse with other colleagues from the team about the emotions I experience beta value 244 .

In public sector hospitals employee's appreciation factors are explaining 23.3\% deviation in employee performance. From the 
ANOVA table it is observed that appreciation factors of transformational leadership are significantly impacting employee performance. Employee performance can be explained by constant value 2.358 and is friendly to the staff beta value .218 , Respects to the rights of the staff beta value .091 , Work is reliable beta value .166 .

From the analysis it is evident that in the study area Emotional Intelligence has partial mediation effect on Transformational Leadership and Employee Performance.

\section{SUGGESTIONS BASED ON THE FINDINGS}

$\checkmark \quad$ In the public sector hospital lowest mean value of patience implies that employees are not patiently responding to patients. The reason behind this is; in public sector hospitals majority of the patients are uneducated and they are not able to understand employees' instructions. For this reason, employees have to repeat the instructions a greater number of times to each patient, this makes employees unpleasant and they cannot be tolerant with all the patients. But employees have to understand one important thing i.e employees' salaries are paid from the amount collected from those patients in the form of Taxes. Therefore, yoga and meditation classes have to be conducted for employees to increase tolerance.

$\checkmark$ From the analysis it is found that in public sector hospitals awareness of emotions is explaining $59.6 \%$ deviation in employee performance. It implies that majority of the employees felt awareness of emotions is very important. As hospital employees are working under hectic schedule it is evident that they may lose emotional balance some times. Therefore, administration has to conduct awareness camps to understand and practice emotional intelligence so as to enhance quality of work life as well as personal life.

$\checkmark$ According to employee's perception in public sector hospitals employee's appreciation factors are explaining $23.3 \%$ deviation in employee performance. Good performance always needs appreciation. No acknowledgement of hard work sometimes discourages employees. Therefore, administration should identify the good performers and appreciate them because in public sector organisations promotions are based on experience rather than performance appraisal; so, administration should acknowledge them and provide non monitory benefits like liberal leave sanctions, flexible working hours etc.

$\checkmark$ From the review literature it is found that transformational leadership has indirect effect on employee performance. In the current study also, it is found that emotional intelligence has mediating effect on transformation leadership and employee performance. Therefore, management has to administer transformational leadership questionnaire and emotional intelligence questionnaire to understand the changes in employee performance.

\section{CONCLUSION}

The current research is conducted to examine the level of employee performance in the study area, to study emotional intelligence impact on employee performance, to study transformational leadership impact on employee performance and mediating effect of emotional intelligence on transformational leadership and employee performance. In public sector hospitals for personality features: interested and compensate, for human skills: suitable relationships with patients, for conceptual skills: take decisions in ambiguous space, for technical skills: perform medical procedures correctly, for rules\& regulations: attention to patient safety registered highest mean value for employee performance. In public sector hospitals awareness of emotions of emotional intelligence factor has highest impact on employee performance, appreciation of transformational leadership factor has high impact on employee performance. From the analysis it is evident that in the study area emotional intelligence has partial mediating effect on transformational leadership and employee performance.

\section{Scope for Future Research}

1. The present research is confined to Hospital sector only; in future researcher may validate the model in other sectors.

2. The present research involved 450 employees of public sector hospitals; in future researchers may involve a greater number of respondents.

3. In future researcher may verify is there any gender impact on the present model.

\section{REFERENCES}

1. Ali Akbar Behbahani (2011). comparative Study of the Relation between Emotional Intelligence and Employee's Performance. Procedia - Social and Behavioral Sciences, 30 (2011) 386 - 389

2. Awang, Z. (2015). SEM made simple: A gentle approach to learning structural equation modelling. Bandar BaruBangi, MPWS Rich Resources.

3. Beckstead, J. W. (2009). Content validity is naught. International Journal of Nursing Studies, 46(9), Pp: 1274-1283.

4. Chin W.W. (1998). Issues and opinion on structural equation modelling. MIS Quarterly, 22 (1), 7-16.

5. Efstathios Bakertzis, Barbara Myloni (2019). What Is the Mediating Role of Job Burnout in the Relationship between Emotional Intelligence and Job Performance in the Healthcare Sector? The International Journal of Business \& Management, Vol 7 Issue 2, Pp: 29- 36. 
6. Fornell, C., \& Larker, D. F. (1981). Evaluating structural equation models with unobservable variables and measurement error. Journal of Marketing Research, 18, 39-50.

7. Goleman, D. (1998). Working with emotional intelligence. New York: Bantam Books.

8. Hair, J. F., Anderson, R. E., Tatham, R. L. and Black, W. C. (1998). Multivariate data analysis. (5th Ed.). Prentice-Hall, New Jersey.

9. Hair, J. F., Black, W. C., Babin, B. J., \& Anderson, R. E. (2010). Multivariate data analysis (7th Ed.). Upper saddle River, New Jersey: Pearson Education International.

10. Jie-Hui Xи (2017). Leadership theory in clinical practice. Chinese Nursing Research, 4 (2017) Pp: 155-157.

11. Krepia V, Katsaragakis $S$, Kaitelidou D, Prezerakos $P$ (2018). Transformational leadership and its evolution in nursing. Prog Health Sci, Vol 8, No 1, Pp: 189- 194

12. Ljerka Hajncl, Dario Vučenović (2020). Effects of Measures of Emotional Intelligence on the Relationship between Emotional Intelligence and Transformational Leadership. Psychological Topics, 29 (2020), 1, Pp: 119134.

13. Owen Doody and Catriona M Doody (2012). Transformational leadership in nursing practice. British journal of nursing, DOI: 10.12968/bjon.2012.21.20.1212 . Source: PubMed

14. Ranjbar Ezzatabadi M, Bahrami MA, Hadizadeh $F$, Arab M, Nasiri S, Amiresmaili $M$, et al. (2012). Nurses' Emotional Intelligence Impact on the Quality of Hospital Services. Iran Red Cres Med J. 2012; 14(12):758-63. DOI: 10.5812/ircmj.926.

15. Rukmathan R and V. Kavitha (2019). A Study on Impact of Emotional Intelligence with Job Performance of Nurses in Coimbatore. MERC Global's International Journal of Management, Volume 7, Issue 4, Pp. 301-306

16. Sakshi Singh, Raminder Kalra, Sherly Thomas (2019). Relationship between Emotional Intelligence and Job Performance Satisfaction as Perceived by the Nursing Personnel. International Journal of Science and Research, Volume 9 Issue 4, Pp: 1677- 1679. DOI: 10.21275/SR20422115822.

17. Siahaan, Elisabeth, Gultom, Parapat\& Lumbanraja, P. (2016). Improvement of employee banking performance based on competency improvement and placement working through career development (case study in Indonesia). International Business Management, Vol: 10, Pp: 255- 261. DOI 10.3923/ibm.2016.255.261.

18. SuhailaHaron, Aini Suzana Ariffin, Durrishah Idrus (2019). Validating the Development of Instrument for Measuring Nurses' Performance Scale. Journal of Management Info, Vol $6 \mathrm{No}$ 1(2019); Pp: 31-38.

19. Sunardi Idi, Nur Hidayah (2020). The Influence of Leadership on Work Motivation and Its Effect on Nurses' Performance in Ward Unit of Morotai Island District Hospital. RA Journal of
Applied Research, Volume 06 Issue 02, Pp: 2654-2658.

20. Vishnu Renjith, Renu G, Anice George (2014). Transformational Leadership in Nursing. International Journal of Scientific Research and Management Studies, Volume 2 Issue 2, Pp: $112-118$ 